\title{
Nickel and Palladium Catalyzed Olefin Polymerization
}

\author{
Qiuli Wang ${ }^{1,2}$, Binnian Yuan ${ }^{1,3}$, Guoyong $\mathrm{Xu}^{1}$ and Fuzhou Wang ${ }^{1 *}$ \\ ${ }^{1}$ Institutes of Physical Science and Information Technology, Anhui University, China \\ 2Jiaxiang No.1 Middle School, China \\ ${ }^{3}$ China University of Mining and Technology Yinchuan College, China
}

Submission: January 10, 2019; Published: January 22, 2019

*Corresponding author: Fuzhou Wang, Institutes of Physical Science and Information Technology, Anhui University, Hefei 230601, Anhui, China.

\begin{abstract}
This review summarized the progress on transition metal catalysts for olefin polymerization, and focuses on the olefin polymerization by the late transition metal catalysts and the recent advances in catalyst design. In recent years, nickel and palladium complexes for olefin polymerization have received extensive researches owing to the precise control of branching microstructure, molecular weights and properties of the resulting polyolefins.

Keywords: Nickel and palladium complexes; Olefin polymerization; Chain-walking; Branched polymer

Abbrevations: MAO: Methylaluminoxane; CGC: Constrained Geometry Catalysts; LDPE: Low Density Polyethylene; LLDP: Linear Low-Density Polyethylene; HDPE: High-Density Polyethylene; PP: Polypropylene
\end{abstract}

\section{Introduction}

The research of the ethylene and $\alpha$-olefins polymerizations using late transition metal catalysts should be highlight for development of polyolefin materials during the past two decades [1-5], because polyolefin materials are tremendously important in daily life [6]. Branched polyolefins are generally produced by transition-metal catalyzed copolymerization. The physical properties of polyolefin materials can be dramatically affected by their microstructures, which are controlled by the catalyst structures and their catalytic behavior. Progress of molecular the catalysts of transition metal complexes during these three decades enabled control of stereochemistry of poly( $\alpha$-olefin)s, control of molecular weight of polyethylene and poly( $\alpha$-olefin) $\mathrm{s}$, synthesis of block copolymers by living polymerization, and copolymerization with various comonomers including polar functionalized olefins [5]. Thus, the design and synthesis of novel transition metal catalyst has always been a research focus of the polyolefin research.

In 1950s, Ziegler \& Natta discovered that the mixture of titanium chloride and alkyl aluminum compounds enabled polymerization of ethylene and propylene, the synthesis of High Density Polyethylene (HDPE) and isotactic polypropylene, respectively. The discovery of [7] catalysts (Figure 1) not only revolutionized polyolefin production, but also catalyzed the development of the entire organometallic chemistry field.
In 1980s, Kaminsky [8] discovered that Methyl Aluminoxane (MAO) as an excellent co-catalyst to highly activate halfmetallocene's [8] and badged metallocene catalysts for alkene polymerization to produce polymers of narrow molecular weight distribution. The second milestone in alkene polymerization catalysis was the development of metallocene catalysts.

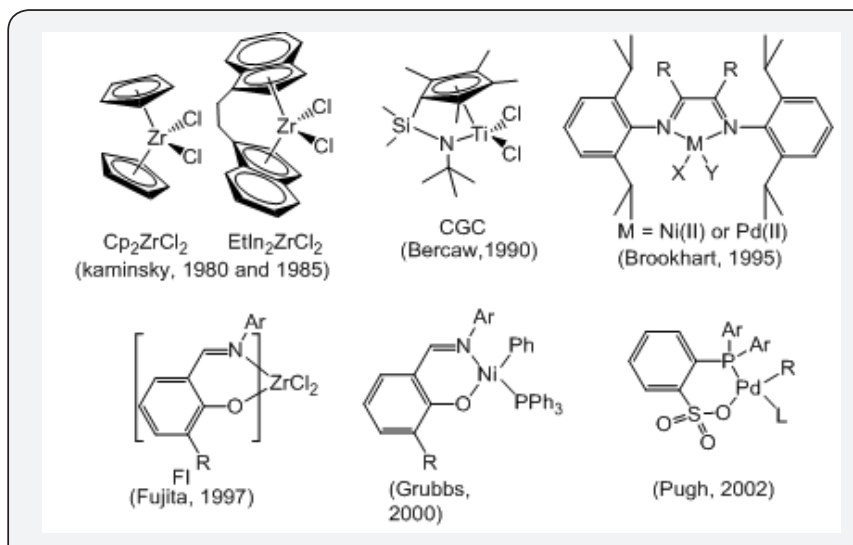

Figure 1: The typical structure of transition metal catalysts for olefin polymerization.

In 1990s, Bwren reported that the constrained geometry catalysts (CGC, Figure 1) [9] exhibited their unique properties in the catalysis and revealed the relationship between the structure 
of the catalysts and stereoselectivity of the reaction, and showed high activity for ethylene and 1-alkene copolymerization. In addition, Fujita also reported that the bis(imine-phenoxy) titanium and zirconium complexes (FI catalysts, Figure 1) exhibited high activity for ethylene polymerization [10].

In 1995, Brookhart [11] discovered that nickel and palladium complexes with bulky diimine ligands showed high catalytic activity for ethylene and $\alpha$-olefin polymerizations [11] to produce high molecular weight polyethylene with different polymer topologies and branched poly( $\alpha$-olefin)s [12-13]. Interestingly, these nickel and palladium catalysts are also used for copolymerization of ethylene with polar monomers to afford the copolymers possessing functional groups in a single step because of their good tolerance toward polar functionality [14,15].

The discovery of late transition metal nickel and palladium catalysts has initiated a new olefin polymerization field. In 1998, Gibson [16] and Brookhart [17,18] reported that Fe and Co catalysts with bis (imino) pyridine catalyzed ethylene polymerization efficiently to afford linear polyethylene. In 2000, Grubbs [19] reported that neutral nickel catalysts [19] containing salicylaldimine ligand are used for polymerization of ethylene. In 2002, Pugh [20] reported that palladium catalysts with phoshine sulfonate ligand can produce unique polymers such as a highly linear copolymer of ethylene and alkyl acrylates [20] and a nonperfectly alternating copolymer of ethylene and CO [21].

In this review, recent progress on late transition metal catalysts for ethylene or $\alpha$-olefin polymerizations are summarized [1]. Systematical study elucidated the effects of late transition metal ion, $\alpha$-diimine backbone and the ligand on it, the effects of polymerization conditions (temperature and pressure) on the catalyst's performance, branching degree, molecular weight and its distribution of the polymer and the properties of the polymer produces.

\section{Chain-walking ethylene polymerization by nickel and palladium catalysts}

The research of the ethylene polymerization catalyzed by late transition metal catalyst should be highlight for development of polyolefin materials in recent years [22-28], because polyethylene is probably the polymer you see most in daily life. There are three main types of polyethylene namely: Low Density Polyethylene (LDPE), Linear Low-Density Polyethylene (LLDP) and HighDensity Polyethylene (HDPE).

\section{Chain-walking ethylene polymerization mechanism}

The discovery of nickel and palladium $\alpha$-diimine catalysts (Figure 2) by Brookhart et al. [11] in the 1990s is another further major advance in the alkene polymerization catalysis [11-13]. Distinctly different from other catalysts, this unique series of late transition metal catalysts is featured with their characteristic chain-walking mechanism and allow the unprecedented one-step synthesis of polyethylenes with controllable chain topology [2933].

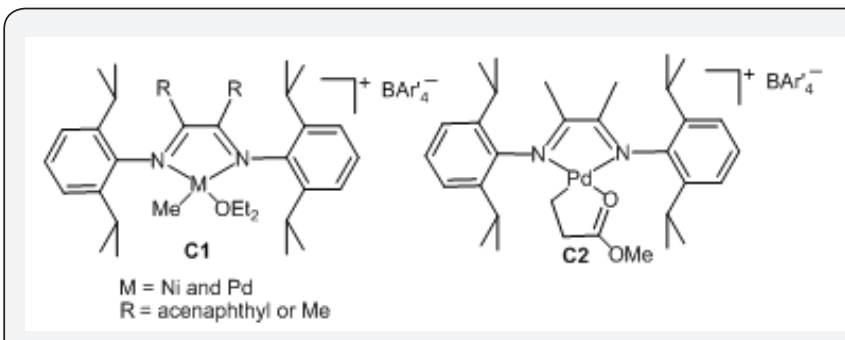

Figure 2: Brookhart's catalysts for olefin polymerization.

The nickel and palladium $\alpha$-diimine catalysts C1 and C2 (Figure 2) showed high activity for polymerization to produce different branched polymers, depending on the catalyst structures and the polymerization conditions (temperature and ethylene pressure), because the the ability of the propagating metal-alkyl species to migrate along the growing polymer chain via rapid $\beta$-hydride elimination and reinsertion (chain-walking, (Figure 2) [34-37]. The formation of the major types of branches including the methyl, ethyl, propyl, butyl, sec-butyl and longer chains, in the branched polyethylene $[36,38]$. The mechanism of chain-walking for ethylene polymerization is shown in (Figure 3).

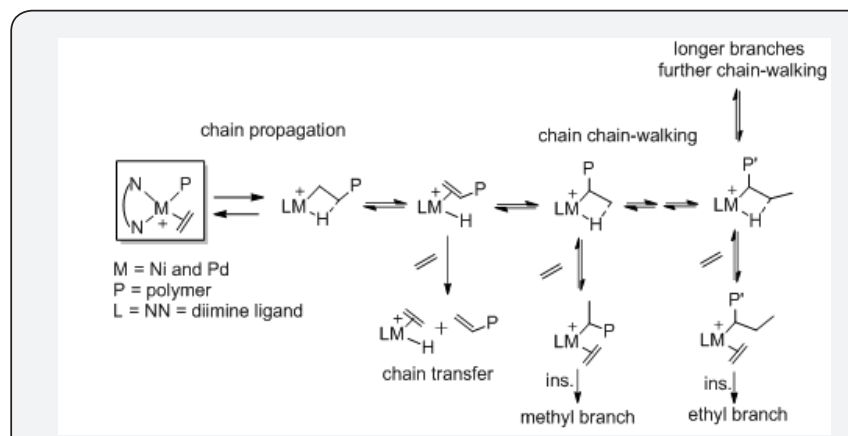

Figure 3: Chain-walking mechanism for ethylene polymerization with $\alpha$-diimine nickel and palladium catalysts.

The degree of the polyethylene branching can be controlled via polymerization conditions $[1,39]$ as follows. For example, Guan et al. $[40,41]$ demonstrated that ethylene pressure has been used to control the competition between monomer insertion and chainwalking processes for ethylene coordination polymerization catalyzed by a palladium $\alpha$-diimine catalyst C2. The topology of the polyethylene changed from linear polyethylene with moderate branches at high ethylene pressures to a hyperbranched polyethylene at low pressures.

\section{Modified nickel and palladium catalysts}

Previous studies showed that sterically bulky ligands are usually required to afford nickel and palladium catalysts capable of generating high activity, stability and high molecularweight polymers [42-48]. Besides, linear polyethylene via chain straightening mechanism is the most abundantly produced plastic owing to its inexpensive monomer, thermoplastic properties, and semi-crystalline nature [1]. The degree of the polyethylene branching can be controlled via catalyst structures and polymerization conditions. For example, Schmid etal. [49] reported a new "Ortho-Aryl Esffect" using terphenyl substituted 1,4-diaza- 
1,3-butadiene ligands: the corresponding nickel complexes C3 were highly active catalysts for ethylene homopolymerization to produce almost perfectly linear polyethylene's in the presence of hydrogen [49].

Guan et al. [50-52] designed the macrocyclic ligand by connecting the aryl substituents of 2,6-diarylphenylimino moieties using ethylene tether. Their cyclophane-based nickel and palladium catalysts C4 showed significantly higher thermal stability than the acyclic analogs [49-52]. The palladium catalysts also generated polymers with significantly high branching density compared to the acyclic counterparts, suggesting faster chain-walking process [50]. The cyclophane-based nickel catalyst promoted living polymerization of propylene even at $50-75^{\circ} \mathrm{C}[51]$. This type of catalyst enhances both the 2,1-insertion of propylene and the chain-walking reaction. The branching density of the generated Polypropylene (PP) is slightly above 100/1000C, which is only half of the value comparing with conventional $\alpha$-diimine nickel catalyst. Besides, the palladium catalyst incorporated a much higher amount of Methyl Acrylate (MA) than the acyclic analogue (Figure 4).

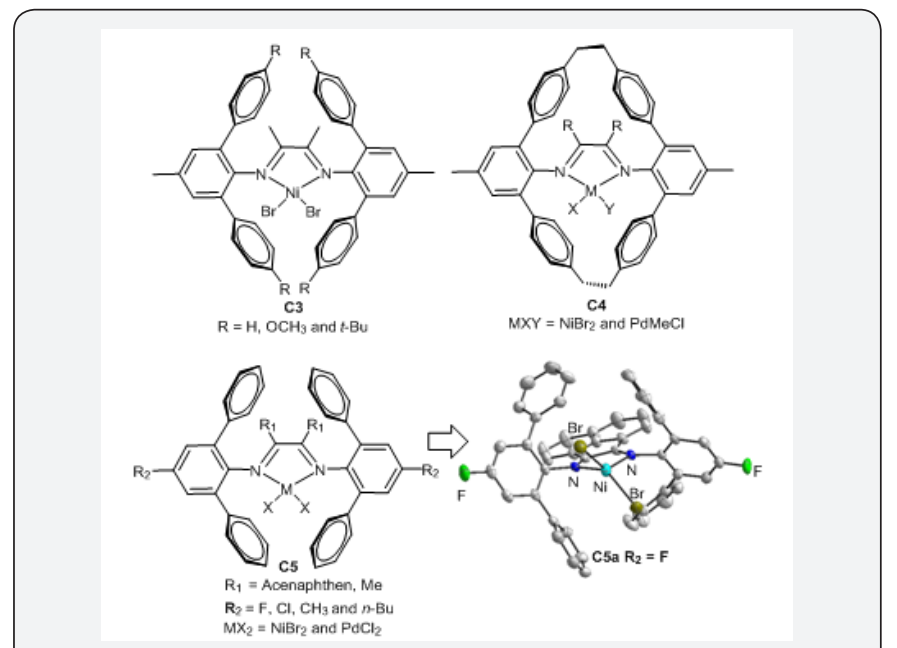

Figure 4: Structure of ortho-teraryl-substituted a-diimine nickel and palladium complexes.

Inspired by these works, we recently reported a series of $\alpha$-diimine nickel and palladium complexes C5 [53,54] containing 2,6-diphenyl groups. These nickel complexes exhibited high catalytic activity in the polymerization of ethylene (up to 106g PE/ (mol Ni h bar)) and produced highly-branched polyethylenes at high temperature upon activation with Et2AlCl. The introduction of an electron-withdrawing group to the ligand framework improves the catalytic activity significantly. We also reported a series of $\alpha$-diimine nickel complexes [35,37,42] containing paraphenyl or para-naphthyl substituents for ethylene polymerization under low ethylene pressure. These nickel complexes also exhibited high catalytic activity and produced highly-branched polyethylenes.

Brookhart et al. [55] reported a "sandwich" $\alpha$-diimine nickel catalyst C6a incorporating two 8-p-tolylnaphthylimino groups which provide exceptional shielding of the two axial sites were shown to produce highly branched polyethylene (up to 152 branches/1000C) [55] with ultra-high-molecular-weight. Recently, they also studied a "sandwich"-type diimine palladium catalyst $\mathrm{C} 6 \mathrm{~b}$ for ethylene polymerization, the catalyst conducted living polymerization at $25^{\circ} \mathrm{C}$ and produced hyperbranched polymers [56] (Figure 5).

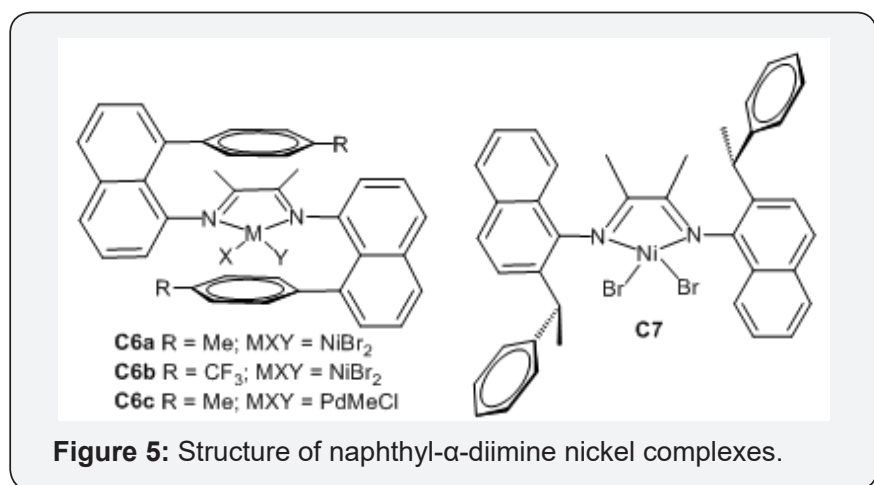

Coates et al. reported that the precision chain-walking polymerization of higher $\alpha$-olefins using the "sandwich" $\alpha$-diimine nickel catalyst C6c [57] and some derivative catalysts to afford highly "chain-straightened" semicrystalline polymers (Tm > $100^{\circ} \mathrm{C}$ ) with a significant fraction of $1, \omega$-enchainments. We have reported that a similar naphthyl- $\alpha$-diimine nickel catalyst C7 bearing chiral bulky sec-phenethyl groups in the o-naphthyl position, activated by Et2AlCl [58], showed highly catalytic activity for the polymerization of ethylene $(2.81 \times 106 \mathrm{~g} \mathrm{PE}(\mathrm{mol}$ Ni h bar) -1) and produced branched polyethylene. Interestingly, C7 could Produce Syndiotactic PMMA at low temperature (rr up to $88.75 \%,-30^{\circ} \mathrm{C}$ ).

\section{Conclusion}

In this review, the progress on transition metal catalysts for olefin polymerization were summarized. We first briefly discussed the chain walking mechanism of nickel and palladium catalysts in ethylene polymerization. Subsequently, some recent advances in the $\alpha$-diimine-based nickel and palladium catalysts development were summarized. Specifically, the modifications on $\mathrm{N}$-aryl substituents were described.

\section{Acknowledgements}

This work was supported by the National Natural Science Foundation of China (NSFC, 21801002), and the Natural Science Foundation of Anhui Province (No. 1808085MB47).

\section{References}

1. Guo L, Dai S, Sui X, Chen C (2016) Palladium and nickel catalyzed chain walking olefin polymerization and copolymerization. ACS Catal 6(1): 428-441.

2. Guo L, Liu W, Chen C (2017) Late transition metal catalyzed $\alpha$-olefin polymerization and copolymerization with polar monomers. Mater Chem Front 1: 2487-2494.

3. Wang Z, Liu Q, Solan GA, Sun WH (2017) Recent advances in $\mathrm{Ni}$ mediated ethylene chain growth: nimine-donor ligand effects on 
catalytic activity, thermal stability and oligo-/polymer structure. Coord Chem Rev 350: 68-83.

4. Chen C (2018) Redox controlled polymerization and copolymerization. ACS Catal 8(6): 5506-5514.

5. Chen C (2018) Designing transition metal catalysts for olefin polymerization and copolymerization: beyond electronic and steric tuning. Nat Rev Chem 2: 6-14.

6. Malpass DB (2010) Introduction to industrial polyethylene. Wiley, Hoboken, NJ, USA.

7. Whiteley KS (2002) Polyolefins-polyethylene. Ullmann's Encyclopedia of Industrial Chemistry, Inter Science Wiley-VCH Verlag GmbH.

8. Sinn H, Kaminsky W, Vollmer HJ, Woldt R (1980) Living polymers on polymerization with extremely productive ziegler catalysts. Angew Chem Int Ed Engl 19(5): 390-392.

9. Shapiro PJ, Bunel EE, Schaefer WP, Bercaw JE (1990) Scandium complex [\{(. eta. 5-C5Me4) Me2Si (. eta.1-NCMe3) $\}(\mathrm{PMe} 3) \mathrm{ScH}] 2$ : a unique example of a single-component. alpha-olefin polymerization catalyst. Organometallics 9(3): 867-869.

10. Mitani M, Saito J, Ishii S, Nakayama Y, Macio H, et al. (2004) FI Catalysts: new olefin polymerization catalysts for the creation of value-added polymers. Chem Rec 4(3): 137-158.

11. Johnson LK, Killian CM, Brookhart M (1995) New Pd (II)-and Ni (II)based catalysts for polymerization of ethylene and alpha-olefins. J Am Chem Soc 117(23): 6414-6415.

12. Johnson LK, Mecking S, Brookhart M (1996) Copolymerization of ethylene and propylene with functionalized vinyl monomers by palladium (II) catalysts. J Am Chem Soc 118(1): 267-268.

13. Gates DP, Svejda SA, Onate E, Killian CM, Johnson LK, et al. (2000) Synthesis of branched polyethylene using ( $\alpha$-diimine) nickel (II) catalysts: influence of temperature, ethylene pressure, and ligand structure on polymer properties. Macromolecules 33(7): 2320-2334.

14. Mecking S, Johnson LK, Wang L, Brookhart M (1998) Mechanistic studies of the palladium-catalyzed copolymerization of ethylene and $\alpha$-olefins with methyl acrylate. J Am Chem Soc 120(5): 888-899.

15. Popeney CS, Camacho DH, Guan Z (2007) Efficient incorporation of polar comonomers in copolymerizations with ethylene using a cyclophane-based Pd (II) $\alpha$-diimine catalyst. J Am Chem Soc 129(33) 10062-10063.

16. Britovsek GJP, Gibson VC, McTavish SJ, Solan GA, White AJP, et al. (1998) Novel olefin polymerization catalysts based on iron and cobalt. Chem Commun 7: 849-850.

17. Killian CM, Tempel DJ, Johnson LK, Brookhart M (1996) Living polymerization of $\alpha$-olefins using $\mathrm{Ni}_{\mathrm{II}}-\alpha$-diimine catalysts. Synthesis of new block polymers based on $\alpha$-olefins. Am Chem Soc 118(46): 11664 11665.

18. Small B L, Brookhart M (1998) Iron-based catalysts with exceptionally high activities and selectivities for oligomerization of ethylene to linear $\alpha$-olefins. J Am Chem Soc 120(28): 7143-7144.

19. Younkin TR, Connor EF, Henderson JI, Friedrich SK, Grubbs RH, et al (2000) Neutral, single-component nickel (II) polyolefin catalysts that tolerate heteroatoms. Science 287(5452): 460-462.

20. Drent E, Dijk R, Ginkel R, Oost B, Pugh RI (2002) Palladium catalysed copolymerisation of ethene with alkylacrylates: polar comonomer built into the linear polymer chain. Chem Commun 7: 744-745.

21. Drent E, Dijk R, Ginkel R, Oost B, Pugh RI (2002) The first example of palladium catalysed non-perfectly alternating copolymerisation of ethene and carbon monoxide. Chem Commun 9: 964-965.

22. Vaidya T, Klimovica K, LaPointe AM, Keresztes I, Lobkovsky EB, et al. (2014) Secondary alkene insertion and precision chain-walking: a new route to semicrystalline "polyethylene" from $\alpha$-olefins by combining two rare catalytic events. J Am Chem Soc 136(20): 7213-7216.

23. Wang FZ, Yuan JC, Song FY, Li J, Jia Z, et al. (2013) New chiral $\alpha$-diimine nickel (II) complexes bearing ortho-sec-phenethyl groups for ethylene polymerization. Appl Organometal Chem 27(6): 319-327.

24. Yuan JC, Song FY, Li J, Jia Z, Wang FZ, et al. (2013) Chiral \{bis [N, N'(2-ethyl-6-methylphenyl)imino]-1,2-dimethylethane\}dibromonickel bearing sec-phenethyl groups: synthesis, characterization and application in synthesis of nanosized dendritic polyethylene. Inorganica Chimica Acta 400: 99-106

25. Dai SY, Sui XL, Chen CL (2015) Highly robust Pd (II) $\alpha$-diimine catalysts for slow-chain-walking polymerization of ethylene and copolymerization with methyl acrylate. Angew Chem Int Ed 54(34): 9948-9953.

26. Dai SY, Chen CL (2016) Direct synthesis of functionalized highmolecular-weight polyethylene by copolymerization of ethylene with polar monomers. Angew Chem Int Ed 55(42): 13281-13285.

27. Guo LH, Zou C, Dai SY, Chen CL (2017) Direct synthesis of branched carboxylic acid functionalized poly(1-octene) by $\alpha$-diimine palladium catalysts. Polymers 9(4): 122.

28. Li M, Wang XB, Luo Y, Chen CL (2017) A Second-coordinationsphere strategy to modulate nickel- and palladium-catalyzed olefin polymerization and copolymerization. Angew Chem Int Ed 56(38): 11604-11609.

29. Lian K, Zhu Y, Li W, Dai SY, Chen CL (2017) Direct synthesis of thermoplastic polyolefin elastomers from nickel catalyzed ethylene polymerization. Macromolecules 50(16): 6074-6080.

30. Na YN, Dai SY, Chen CL (2018) Direct synthesis of polar-functionalized linear low-density polyethylene (LLDPE) and low-density polyethylene (LDPE). Macromolecules 51(11): 4040-4048.

31. Fang J, Sui XL, Li YG, Chen CL (2018) Synthesis of polyolefin elastomers from unsymmetrical $\alpha$-diimine nickel catalyzed olefin polymerization. Poly Chem 9: 4143-4149.

32. Zhou SX, Chen CL (2018) Synthesis of silicon-functionalized polyolefins by subsequent cobalt-catalyzed dehydrogenative silylation and nickelcatalyzed copolymerization. Sci Bull 63(7): 441-445.

33. Dai SY, Chen CL (2018) Palladium-catalyzed direct synthesis of various branched, carboxylic acid-functionalized polyolefins: Characterization, derivatization, and properties. Macromolecules 51(17): 6818-6824.

34. Wang FZ, Yuan JC, Li QS, Tanaka R, Nakayama Y, et al. (2014) New nickel (II) $\alpha$-diimine complexes bearing phenyl and sec-phenethyl groups: synthesis, characterization and ethylene polymerization behaviour. Appl Organometal Chem 28(7): 477-483.

35. Wang FZ, Tanaka R, Cai ZG, Nakayama Y, Shiono T (2016) Synthesis of highly branched polyolefins using phenyl substituted $\alpha$-diimine Ni (II) catalysts. Polymers 8(4): 160-175

36. Sun J, Wang FZ, Li W, Chen M (2017) Ligand steric effects on $\alpha$-diimine nickel catalyzed ethylene and 1-hexene polymerization. RSC Adv 7: 55051-55059.

37. Wang FZ, Li R, Tian S, Lian K, Guo D, et al. (2018) Synthesis of highly branched polyethylene using para-phenyl substituted $\alpha$-diimine nickel catalysts. Appl Organomet Chem 32(4): e4298.

38. Tian S, Zhang Y, Li R, Wang FZ, Li W (2019) Cationic para-benzhydryl substituted $\alpha$-diimine nickel catalyzed ethylene and 1-decene polymerizations via controllable chain-walking. Inorganica Chimica Acta 486: 492-498.

39. Li R, Sun J, Tian S, Zhang Y, Guo D, e al. (2019) Synthesis of highly branched polyethylene using para-benzhydryl substituted iminopyridyl Ni (II) and Pd (II) complexes. J Organomet Chem 880: 261-266. 
40. Guan Z, Cotts PM, McCord EF, McLain SJ (1999) Chain walking: a new strategy to control polymer topology. Science 283: 2059-2062.

41. Guan Z (2003) Control of polymer topology through late-transitionmetal catalysis. J Polym Sci Part A: Polym Chem 41(22): 3680-3692.

42. Yuan J, Jia Z, Li J, Song F, Wang FZ, et al. (2013) Nickel (II)- $\alpha-$ diimine complexes containing naphthyl substituents for ethylene polymerization under low ethylene pressure. Transition Metal Chemistry 38(3): 341-350.

43. Dai SY, Sui XL, Chen CL (2016) Synthesis of high molecular weight polyethylene using iminopyridyl nickel catalysts. Chem Commun 52: 9113-9116.

44. Wang FZ, Tanaka R, Cai ZG, Nakayama Y, Shiono T (2016) Precision chain-walking polymerization of trans-4-octene catalyzed by $\alpha$-diimine nickel (II) catalysts bearing ortho-sec-phenethyl groups. Macromo Rapid Commun 37(16): 1375-1381.

45. Wang R, Zhao M, Chen CL (2016) Influence of ligand second coordination sphere effects on the olefin (co)polymerization properties of $\alpha$-diimine Pd (II) catalysts. Poly Chem 7: 3933-3938.

46. Wang FZ, Tanaka R, Cai Z G, Nakayama Y, Shiono T (2017) Living polymerization of higher 2-alkene with $\alpha$-diimine nickel catalysts Synthesis and characterization of high molecular weight poly(2 alkene) s Polymer 127(3): 88-100

47. Wang FZ, Tanaka R, Li QS, Nakayama Y, Shiono T (2018) Chain-walking polymerization of linear internal octenes catalyzed by $\alpha$-diimine nickel catalysts. Organometallics 37(9): 1358-1367.

48. Wang RK, Sui XL, Pang WM, Chen CL (2016) Ethylene polymerization by xanthene bridged dinuclear $\alpha$-diimine Ni (II) complexes. Chem Cat Chem 8(2): 434-440.

49. Schmid M, Eberhardt R, Klinga M, Leskela M, Rieger B (2001) New $\mathrm{C}_{2 \mathrm{v}}$ - and chiral $\mathrm{C}_{2}$-symmetric olefin polymerization catalysts based on nickel (II) and palladium (II) diimine complexes bearing 2,6-dipheny aniline moieties: synthesis, structural characterization, and first insight into polymerization properties. Organometallics 20(11): 2321 2330 .
50. Camacho DH, Salo EV, Ziller JW, Guan Z (2004) Cyclophane-based highly active late-transition-metal catalysts for ethylene polymerization. Angew Chem Int Ed 43(14): 1821-1825.

51. Camacho DH, Guan Z (2005) Living polymerization of $\alpha$-olefins at elevated temperatures catalyzed by a highly active and robust cyclophane-based nickel catalyst. Macromolecules 38(7): 1089-1092.

52. Popeney CS, Levins CM, Guan Z (2011) Systematic investigation of ligand substitution effects in cyclophane-based nickel (II) and palladium (II) olefin polymerization catalysts. Organometallics 30(8): 2432-2452.

53. Yuan JC, Wang FZ, Yuan BN, Jia Z, Song FY, et al. (2015) Highly active ortho-phenyl substituted $\alpha$-diimine nickel(II) catalysts for "chain walking polymerization" of ethylene: Synthesis of the nanosized dendritic polyethylene. J Mol Catal A Chem 370:132-139.

54. Wang FZ, Tanaka R, Li QS, Yuan JC, Nakayama Y, et al. (2015) Synthesis and application of $\alpha$-diimine Ni (II) and Pd (II) complexes with bulky steric groups to polymerization of ethylene and methyl methacrylate. J Mol Catal A Chem 398: 231-240.

55. Zhang D, Nadres ET, Brookhart M, Daugulis 0 (2013) Synthesis of highly branched polyethylene using "sandwich" (8-p-tolyl naphthyl $\alpha$-diimine) nickel(II) catalysts. Organometallics 32(18): 5136-5143.

56. Allen KE, Campos J, Daugulis O, Brookhart M (2015) Living polymerization of ethylene and copolymerization of ethylene/methyl acrylate using "sandwich" diimine palladium catalysts. 5(1): 456-464.

57. Vaidya T, Klimovica K, LaPointe AM, Keresztes I, Lobkovsky EB, et al (2014) Secondary alkene insertion and precision chain-walking: A new route to semicrystalline "polyethylene" from $\alpha$-olefins by combining two rare catalytic events. J Am Chem Soc 136(20): 7213-7216.

58. Yuan J C, Wang F Z, Xu W B, Mei T J, Li J, et al. (2013) Chiral naphthyl$\alpha$-diimine nickel (II) catalysts bearing sec-phenethyl groups: chain-walking polymerization of ethylene at high temperature and stereoselective polymerization of methyl methacrylate at low temperature. Organometallics 32(14): 3960-3968.

\section{Your next submission with Juniper Publishers will reach you the below assets}

- Quality Editorial service

- Swift Peer Review

- Reprints availability

- E-prints Service

- Manuscript Podcast for convenient understanding

- Global attainment for your research

- Manuscript accessibility in different formats

(Pdf, E-pub, Full Text, Audio)

- Unceasing customer service

Track the below URL for one-step submission

https://juniperpublishers.com/online-submission.php 